\title{
LOS PRIMEROS PASOS DE LA MEDICINA VETERINARIA EN LAS PALMAS DE GRAN CANARIA (1904-1910)
}

The first steps of Medicine Veterinary in Las Palmas de Gran Canaria (1904-1910)

Martín del Castillo J. F.*

Instituto de Enseñanza Secundaria, I.E.S. ARGUINEGUíN, Mogán, Gran Canaria, España.

*Autor para correspondencia: Juan Francisco Martín del Castillo, Email: martinica02@eresmas.com

\section{RESUMEN}

Entre 1904 y 1910 se define el servicio veterinario municipal en Las Palmas de Gran Canaria. Es una etapa fundacional, sellada por la improvisación del gobierno local, el amateurismo de las conductas y las necesidades de garantizar un orden básico en la dotación de plazas de Profesor Veterinario y, sobre todo, la de procurar la sanidad animal en el territorio. En el presente, se analiza este proceso que transcurre desde la aceptación de la normativa legal del ramo, con todas sus consecuencias, hasta el definitivo afán preventivo. Por encima de la breve trama veterinaria, se advierten las claves históricas del reformismo de principios de siglo en el archipiélago canario.

Palabras clave: Veterinaria, Medicina, Sanidad, Reformismo, España, Las Palmas de Gran Canaria (Islas Canarias), Siglo XX.

\begin{abstract}
The official veterinary service in Las Palmas de Gran Canaria was established between 1904 and 1910. In its beginnings, the local authority was forced to improvise and suffered from lack of experience, in an effort to procure veterinary teaching positions and most importantly, a veterinary service to cover the needs across its territory. This article analyses the process from its early days characterised by the implementation of legislation and a strong desire to put in place disease prevention strategies. Attitudes were markedly tainted by the reformist spirit that characterised the beginning of the century in the Canarian Archipelago.
\end{abstract}

Keywords: Veterinary, Medicine, Health, Regenerationism, Spain (Canary Islands), XX Century. 


\section{INTRODUCCIÓN}

A principios del siglo $\mathrm{XX}$, y con motivo de la llegada al gobierno local de señalados individuos en lo social y en lo político, se dejan sentir aires de renovación en la periferia insular española. Desde luego, el fenómeno obedece, en lo general, a una propuesta de carácter marcadamente regeneracionista ${ }^{1}$, en la denominación exitosa de la época y proveniente, entre otros, de los escritos del polifacético y profético Joaquín Costa $^{2}$, y que, en las Islas Canarias, también cautiva y protagoniza ciertas conductas señeras. El regeneracionismo toma, en el ámbito canario, unas connotaciones voluntaristas y humanitarias, que lo hacen distintivo, a su modo, en el interior de las vertientes de la gestión social y política. Una de ellas es, por supuesto, la esfera higiénico-sanitaria ${ }^{3}$, que, secundada por la proliferación de la normativa legal, hace firme promesa de una lectura histórica novedosa e interesante por la conjunción de propósitos y enmiendas para los aspectos tradicionales y heredados de sus directas competencias.

Personajes gloriados por actitudes cívicosociales, como los prebostes Ambrosio Hurtado de Mendoza o Felipe Massieu Falcón, ambos alcaldes de la urbe capitalina, en sus respectivos períodos, son los héroes del espíritu regeneracionista, de indudable impronta en la historia local de Las Palmas de Gran Canaria. Esto ya se ha convertido en un aserto de innecesaria demostración, pues se ha trocado en evidencia palmaria de la instantánea histórica proyectada. No obstante, si se ha de precisar, en algún foro, la ubicación regeneracionista del pensamiento

1 Cfr. AVILÉS FARRÉ, Juan et alii (2002). Historia política, 1875-1939. Madrid, Eds. Istmo (Col. "Fundamentos", Serie "Historia de España, XVII"), pp. 171-173.

2 Ibíd., pág. 172.

3 Cfr. MARTÍN DEL CASTILLO, Juan Francisco (2009). La Voluntad de Hipócrates. Principales episodios de la Junta Municipal de Sanidad y la salud pública en Las Palmas de Gran Canaria, 1875-1915. Santa Cruz de Tenerife, Eds. Idea y Sociedad Canaria de Historia de la Medicina. profundo de los ediles, no debería dejarse para el último lugar el intercambio epistolar privado. A su través, y singularmente en el caso de Massieu Falcón, la correspondencia mantenida a lo largo de las décadas, de carácter privado y con abigarrada temática, circunstancia las claves de un ideario de renovación, hábil y literariamente expuesto, en un semillero de perfecta explicitud de una conducta social, que, por sí sola, quizás no estuviera en condiciones de justificarse en su completa dimensión. Por ejemplo, las epístolas remitidas a su sobrino, político en auge, Leopoldo Matos Massieu, muestran la cantera de la que se nutre el particular regeneracionismo doctrinal de don Felipe, en variopintos y sustanciosos comentarios, si bien todos ellos de inusitado interés histórico y político ${ }^{4}$.

En este breve trabajo historiográfico, sin pretender verter la ideología ilustrada de los individuos en el ambiente social, ya que ése no es el objeto perseguido, se procura comprender una serie de claves temporales, teñidas, sin embargo, de las notas ya referidas, en unos campos que, por su alcance o dinámica interna, extrañan al componente del ideario político. Hacemos un esfuerzo por sobreponer un juicio alternativo a esta primera imagen, a nuestro modesto entender no satisfecha por la documentación histórica al uso. En lo concreto, dos conceptos de la evolución social, cuales puedan ser la prevención y el imperante reformismo, se postulan como posibles constantes de un período crucial del crecimiento y definición de la capital grancanaria, poco antes del impacto de la I Guerra Mundial, hito que supone el ocaso de la discusión histórica planteada.

En los terrenos de la sanidad, sea humana o animal (medicina veterinaria), el régimen local propuso una cohorte de medidas, conducentes

4 Véanse las importantísimas misivas intercambiadas entre 1915 y 1921 , de asuntos varios pero con el común denominador de la problemática canaria y, dentro de ella, la política municipal: (A)rchivo (H)istórico (P)rovincial de (L)as (P)almas/ (Fondo Documental) (L)eopoldo (M)atos, legajo 5 . 
a operar un cambio cierto y significativo, que, por su calado e iniciativas, merece ser recordado y analizado desde un punto de vista comprehensivo, más atento a las relaciones de la ciencia médica y la práctica veterinaria que a los desencuentros. El efecto, o esa es nuestra particular pretensión investigadora, es que quede de manifiesto un espíritu renovador, un tanto legalista (su principal débito, nadie lo pone en duda), pero, con todo, forjador de una ruta posteriormente proseguida por los responsables de las áreas.

Este itinerario histórico, abierto en los principios de la centuria, dibuja una línea muy precisa en el diseño de la política sanitaria de aquellos tiempos. Alinear al menos unas cuantas constantes historiográficas del período servirá para hacer un cabal entendimiento de las posturas de los gobernantes y, asimismo, del proceso seguido para obtener una eficaz ejecución de las ideas de los encargados de llevar adelante la gestión sanitaria. De fortuna que, con el concurso del documento oportuno y la veraz y legítima interpretación historiográfica, se procederá a la consecución de un perfil de actuaciones ineludible para sentar las bases de la historia de la sanidad en los albores del siglo $\mathrm{XX}$ en la ultraperiferia insular española.

\section{EL REFORMISMO VETERINARIO: DE LO LEGAL A LO PREVENTIVO (1904-1910)}

La tentativa de una aproximación a la ciencia veterinaria en las Islas Canarias de principios de siglo debe pasar, inevitablemente, por la explicación de las actividades de los profesionales ocupados en el trato y cuidado de los animales domésticos. Por aquel entonces, sobresalía una caótica disposición y organización del servicio en las responsabilidades locales $-y$ no es gratuita la calificación-, por completo ajenas a la exigencia legal de la normativa vigente en cuanto a la provisión de plazas y a la delimitación de las funciones inherentes al oficial veterinario. Tanto era así que lo habitual suponía transferir, en ocasiones rozando el delito administrativo, el modelo militar al plano civil $^{5}$. Quiere decirse que, al no dotarse las vacantes por inexistencia de personal cualificado o por la razón que fuera, se recurría, de manera natural, sin cuestionamientos previos de ninguna índole, a la figura del Profesor Veterinario del cuerpo del Ejército destacado en el lugar. Y éste, en vista de acrecer sus remuneraciones en cantidades respetables, y al sentirse necesario e indispensable a la constitución y mantenimiento del servicio, no dudará en doblar la labor profesional.

En paralelo a esta idiosincrasia, el intrusismo profesional campaba a sus anchas, libre de las cortapisas reguladoras presentes en la mayor parte del estado español. Este fenómeno histórico debe, además por su propia definición, experimentar un juicio interpretativo marcado por la mesura de los análisis, que no quiere decir consentidor de las conductas producidas, por cuanto la veterinaria, en los terrenos puramente académicos o científicos, pugnaba por ser reconocida en el pabellón de las disciplinas universitarias en una paridad total, si bien, en otra latitud, en la vida cotidiana prevalecía la sensación opuesta. Esto es, el albéitar, o sanador de animales, disputaba aptitud y capacidad al veterinario titulado, como han venido demostrando los estudios historiográficos editados hasta el momento ${ }^{6}$.

5 Sobre la evolución de la veterinaria castrense, $c f r$. PÉREZ GARCÍA, J. M. (1995). El Cuerpo de Veterinaria Militar, 1845-1995. Madrid, Ministerio de Defensa.

6 Véanse, al respecto, CORDERO DEL CAMPILLO, M. (1996). Albeytería, mariscalia y veterinaria: orígenes y perspectiva literaria. León, Universidad de León ( Secretariado de Publicaciones); GRATACOS I MASANELLA, Jaume et alii (2000). "Los Menescales y las Menescalías desde el siglo XII al siglo XX", en Col.legi Oficial de Veterinaris de Barcelona (ed.), V Jornadas Nacionales de Historia de la Veterinaria. Barcelona, Col.legi Oficial de Veterinaris de Barcelona; GARCÍA MADERAL, C. (2000). "Los animales en el mundo de brujas y sanadores", en Col. legi Oficial de Veterinaris de Barcelona (ed.), V Jornadas Nacionales de Historia de la Vetrerinaria. Barcelona, Col. legi Oficial de Veterinaris de Barcelona. 
El Ayuntamiento capitalino trasciende esta realidad y compendia el tránsito de un modelo relajado de la función pública hacia una rigurosidad jurídico-legal en la atribución de competencias y deberes profesionales. Otrosí, en un corto período temporal, se aglutinan medidas de refuerzo de la prevención higiénica como resoluciones ejemplarizantes en la organización de las oficinas de veterinaria.

\section{Nombramientos, plazas e intrusismo: el pro- blema de la asignación veterinaria (1904- 1910)}

En los primeros días de 1904, sale a la luz la Ley de Instrucción General de Sanidad (aunque fuera aprobada en el ejercicio anterior), por tantas circunstancias significativa y perfiladora del modelo de atención sanitaria observable en la España de los años previos a la II Repúbli$\mathrm{ca}^{7}$. En lo tocante a las Canarias, ello supuso un notable esfuerzo de adaptación al cambio legislativo y, en no menor medida, una puesta al día del sector en su conjunto, fuese en la higiene humana o en la prevención animal. Tampoco puede preterirse que estas reformas, no por necesarias menos impactantes, llevaron a una gradual confusión y desazón de los profesionales médicos y veterinarios. En las décadas entrantes, tal desafío provocará desencuentros y discordias políticas, si bien el acuerdo llegó finalmente con la creación de los Institutos Provinciales de Higiene, recibidos con expectación y cierta reserva a partes iguales ${ }^{8}$.

El que ahora se abre fue un intenso episodio de actualización jurídico-legal, en vista de situaciones heredadas o sobrevenidas, suscep-

7 Véase el magnífico resumen de la cuestión en HUERTAS, Rafael (2000) "Política sanitaria: de la Dictadura de Primo de Rivera a la II ${ }^{\mathrm{a}}$. República". Revista Española de Salud Pública, 74, pp. 35-43.

8 Cfr. MARTÍN DEL CASTILLO, Juan Francisco (2005). "Los orígenes del Instituto Provincial de Higiene de las Canarias Orientales y la sanidad municipal (1926-1927): cambios estructurales y asistenciales". Asclepio, LVII (2), pp. 129-150. tibles de ser tachadas de anómalas o singularmente interesadas en cuya vorágine administrativa la municipalidad tuvo un claro protagonismo, en posiciones de ambigüedad en la licitud de sus acciones, pese a estar penetradas por la consecución de un beneficio social o higiénicosanitario. Nótese que, en la descripciones documentales que han de suministrar el armazón al argumento histórico, la seña imperante es la recta obediencia al detalle normativo, no obstante las irregularidades de diversa índole que desencadenan el procedimiento de adjudicación de las plazas locales de profesores veterinarios.

La legislación sobre el medio sanitario o veterinario, y ya ha sido dicho, experimentó un apreciable crecimiento con el cambio de centuria. Por esta razón, los ediles deberían exhibir un escrupuloso seguimiento de las normas afectas al ramo, so pena de invalidar sus actuaciones, requerir el reclamo de la Subdelegación de Gobierno o el mismo Gobernador Provincial, y, lo peor, enmarañar la Higiene Pública o la Policía Sanitaria de Animales Domésticos hasta extremos esperpénticos. Por ejemplo, la Real Orden de 29 de Mayo de 1889, la citada Instrucción General de Sanidad (1904) y los consiguientes reglamentos a que dio lugar (como el de marzo de 1906, entre otros), amén del resto de los textos de derecho civil y administrativo pertinentes a la definición del régimen de las funciones, atribuciones y exigencias de los empleados públicos en las labores de atención médica y procura veterinaria. Referido lo cual, se está en condiciones de obtener noticia sobre lo ocurrido en Las Palmas de Gran Canaria en orden a dotarse de una plaza de auxiliar de veterinario municipal entre 1904 y 1906, empero dilatarse hasta 1910.

Los antecedentes históricos son, a este caso, importantes porque devienen en onerosas y rígidas herencias de las que no supo o no quiso desprenderse la administración municipal. Desde 1899, la urbe contaba con dos supuestas plazas de veterinaria, con funciones precisas en la vigilancia y trato de los animales de la urbe, 
destacando la inspección en los interiores del matadero local (edificado en 1860) o en la Plaza del Mercado. Una de ellas, la oficial, estuvo ostentada en todo momento por persona experta y cualificada, amparada por la legalidad y sometida a los rigores de la actividad funcionarial; así, verbigracia, Julio Orive del Moral y José Peig Castelló representaron, en sucesivos períodos, esta etapa de transparencia. Sólo que don Julio, de suyo, fue durante más de veinte años Veterinario Municipal, mientras que su colega, primero, desempeñó el cargo de Subdelegado de Veterinaria para el Distrito de Las Palmas, aunque luego, con la división administrativa del nuevo dibujo gubernativo y local, quedó al frente del Distrito de Triana. La otra, la auxiliar, es la que inundó al Ayuntamiento de Las Palmas en un mar de anomalías y supuestos atropellos a la ley, que necesitó de más de un lustro para enjugarse.

A la muerte de don Julio Orive, pareció que todas las sombras sobre el servicio ya iban a menos. La situación impuso una salida inmediata para la provisión de la plaza de veterinario municipal. Gracias a ella, la historiografía recobra el conocimiento de la realidad de los hechos. La comunicación de uno de los pretendientes al puesto, don Pedro Argüello del Fresno, presentada en el registro de entrada el 5 de agosto de 1909, hace el favor de esclarecer, punto por punto, el especial discurrir de la práctica veterinaria en la localidad:

“(...) Que hallándose vacante una de las dos plazas de Veterinario Titular de ese Municipio, por defunción del malogrado Profesor D. Julio Orive del Moral que la venía desempeñando; y habiendo sido creada por esa Excma. Corporación una de dichas plazas, en el año 1899, a instancias y petición del que suscribe, la cual le fue otorgada sin sueldo hasta el presupuesto próximo venidero, y que por circunstancias que el exponente ignora tampoco se le incluyó su sueldo en el presupuesto siguiente viniendo prestando por este concepto los servicios que dicha Corporación le encomendara por espacio de dos años... Por tanto: Ruego de esa Excma. Corporación se digne tener en cuenta las percepciones y acontecimientos... [a fin de que] se le nombre Inspector de carnes de ese Municipio"9.

De la exacta significación de las palabras, y el ganado crédito del remitente, que con tanta vehemencia y firmeza expone, sólo cabe concluir que la interinidad en la que vivió, al menos, una de las plazas de veterinario en Las Palmas de Gran Canaria fue tolerada y, en cierta manera, alentada y consentida por los responsables máximos del gobierno local. Decir lo contrario, en oposición al tenor verificado, sería transitar por la senda del desconocimiento histórico. Bien vale, pues, una explicación del proceder administrativo de los ediles y documentar lo afirmado por Argüello. Ya, en febrero de 1901, la oficina de Abastos tramita un interesante documento al Alcalde Constitucional, corroborando en todos sus extremos el dictum del mentado:

“(...) por enfermedad de D. Julio Orive, Veterinario Municipal, verse prestando servicio de su clase el Veterinario auxiliar honorario D. Pedro Argüello del Fresno, en la Plaza de Abastos y matadero"

Éste, Argüello del Fresno, entró por la vía honorífica o, por mejor decir, de la declarada interinidad en fuerza de la necesidad de apoyar las labores del Veterinario Titular. Además, por si fuera poco, la principal tarea de su realización era atender a la inspección de carnes, lo que él deseaba obtener del Ayuntamiento ocho

9 AHPLP, Ayuntamiento, Sanidad, legajo 6, expediente 49. Comunicación del 5 de agosto de 1909. Cursivas nuestras. (El cargo de inspector de productos cárnicos fue creado por R. O. del 25 de febrero de 1859).

10 Ibíd. Oficio del Servicio de Abastos, del 27 de febrero de 1901. 
años más tarde, según se ha podido comprobar fehacientemente, como acreditación del ejercicio profesional desempeñado. Entonces, ¿qué acontecimiento causó este fenómeno tan peculiar? Si los hechos responden a la descripción, lo real era que de las dos plazas de titularidad en la Veterinaria Municipal sólo existía una, siendo la otra un estupendo ardid para maniobrar en situaciones de saturación o relevo, por cesantía o enfermedad, amén de natural sostén a la tarea de Orive del Moral. De este modo, la ciudad cubría con la amplitud del servicio sin ver mermada la carga presupuestaria, en bien del municipio, no obstante hacer frontera con tesis de ilicitud manifiesta en la provisión y asignación de los cargos funcionariales del sector.

Comprendido esto, hemos de volver a 1909 y 1910, cuando varios individuos optaron, o esa era la fe de su crédula voluntad, por la supuesta auxiliaría del Inspector de Carnes, cuando jamás había sido convocada la susodicha, al menos con todos los preceptos legales exigibles al procedimiento. Mas, ello se corresponde con una conducta habitual, en aquellas décadas, de la política urbana: dejar, si faltase experto en materia alguna de los servicios estructurales de la localidad, que fueran presentándose de motu proprio, al margen de los tortuosos concursos públicos, ofreciendo aquéllos propuestas o calificaciones en virtud de las cuales decidiría la autoridad civil, al hipotético amparo de la normativa que desarrollaba la autonomía de los concejos para dotarse de personal de confianza. La regularidad de semejantes manejos, antes y después del relato de estos hechos, certifica el posibilismo del Consistorio y la urgencia de dar respuesta a un constante progreso urbanístico y un inusitado crecimiento sociodemográfico no siempre predecible. El rival de Argüello del Fresno demoró un tanto su solicitud, pero, por fin, fue rubricada el 22 de febrero de 1910. Se trataba del Veterinario $2^{\circ}$. del Cuerpo de Veterinaria Militar, con destino en la Comandancia de Artillería de Gran Canaria, don José Ostalé Bosque, que pedía la adjudicación de la plaza de Inspector de Abastos y Matadero por estar vacante la de "veterinario auxiliar". Definitivamente, concurrían dos personas, al parecer de indudable preparación técnica y las suficientes garantías académicas, al anhelado puesto municipal. Sin embargo, el procedimiento, de inesperado desenlace, sólo había comenzado. El dictamen e informe preceptivo de la Comisión de Abastos procuraron una lectura "distinta" de la resolución, habida cuenta que no debía "dilatarse la designación de este profesor auxiliar, pues sobre el veterinario inspector se halla acumulado un excesivo trabajo, al que no en todas ocasiones puede atender debidamente una sola persona por mucho que sea su celo" ${ }^{11}$. Aparte de confirmar el veredicto histórico sobre la práctica veterinaria y la higiene animal en aquel tiempo, describe la especial situación administrativa $\mathrm{y}$, sobre todo, la tremenda necesidad de adquirir los servicios de un nuevo experto. Lo que dista de ser comprensible, a los ojos del presente, es que se proponga a un tercer individuo - un tapado, se diría hoy - , don Juan Téllez y López (1878-1915) ${ }^{12}$, que fuera "Catedrático de la Escuela de Veterinaria de Santiago"13, y además con una gratificación de 750 pesetas, para el desempeño de la plaza auxiliar.

Últimamente, el 23 de febrero, la sesión ordinaria del Consistorio tomó por unanimidad un acuerdo, sancionando al detalle lo informado

11 Ibíd. Dictamen e informe, de fecha 18 de febrero de 1910, dirigidos ambos al Alcalde-Presidente.

12 Ibíd. También conocido como Jutelo en los ambientes periodísticos de la capital y, por extensión, en los medios intelectuales, en los que solía prodigarse con profusión y gusto, debido a su condición de novelista (por ejemplo, fue autor de Vidas sin vida: novela, de 1915, o la tempranera De espaldas al Sol, al parecer de 1900, entre numerosos tratados de la especialidad veterinaria o de la Zootecnia).

13 Ibíd. Obtenida en 1904 por este veterinario madrileño, hijo, asimismo, de otro importante académico de la disciplina, don Juan Téllez y Vicén (1830-1885), Catedrático de Patología en la Universidad de León. Al respecto del primero, es importante la consulta de RODRÍGUEZ GARCÍA, M. (1994). Historia da Escola de Veterinaria de Santiago de Compostela. Santiago de Compostela, Universidade de Santiago. 


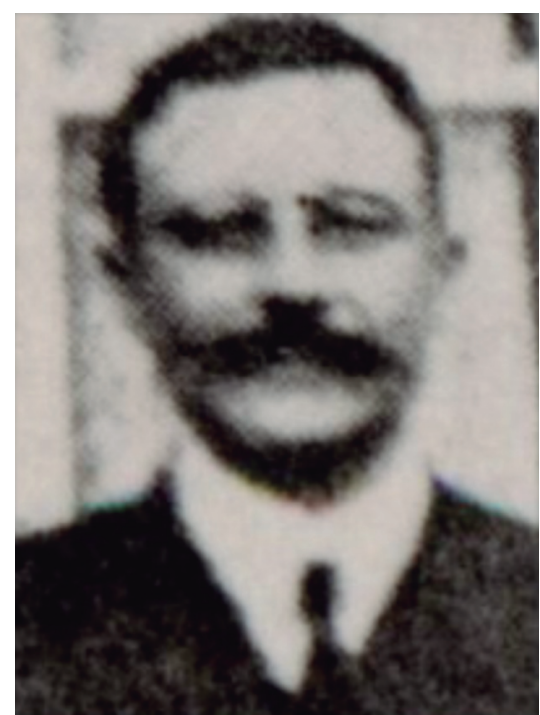

Fotografía de Juan Téllez López (Jutelo).

por la Comisión de Abastos, esto es, "nombrar á D. Juan Téllez y López auxiliar de la inspección de carnes"14, con el estipendio anual ya señalado, y advirtiendo que, en caso de no encontrarse en la isla, fuera sustituido por Ostalé Bosque. A los efectos oportunos, aun se expidió el título de Veterinario Auxiliar ${ }^{15}$. Desde este mismo instante, la irregularidad procedimental tropezó con el estamento encargado de salvaguardar las garantías legales básicas, el Gobierno Civil de la Provincia de Canarias, que no desistió en depurar las responsabilidades a que había lugar con evidente firmeza y prontitud.

Un mes justo tardó en reaccionar el Gobernador Civil, un tiempo récord desde el punto de vista histórico, e incluso administrativo, si se conoce con antelación el tempo de las resoluciones jurídicas de aquellas fechas. Tan diá-

14 Ibíd. Acuerdo del 23 de febrero de 1910.

15 Ibíd. El Alcalde-Presidente, Felipe Massieu Falcón, firmó el documento acreditativo el 24 de febrero de 1910. La certificación administrativa rezaba así: "Título de Veterinario auxiliar de la inspección de carnes de esta Ciudad a favor de Don Juan Téllez y López”. fanamente apreciaba la ausencia de correspondencia con las disposiciones legales preceptivas en materia de contratación y empleo público. La autoridad participa lo dicho por la Junta de Gobierno y Patronato de Veterinarios Titulares, enterada del clamoroso desafuero cometido, y ordena al Alcalde de Las Palmas lo próximo:

"proceder á la destitución del Veterinario Militar [Téllez López], nombrando en su lugar otro del orden civil que desempeñe la inspección con carácter de interino, hasta que sea nombrado en propiedad otro, mediante el oportuno concurso"16.

Se conoce que uno de los optantes a la futura plaza de auxiliar, o bien Argüello del Fresno o bien Ostalé Bosque ${ }^{17}$, formalizó la denuncia ante la máxima instancia de la veterinaria civil, desbrozándose los hechos según el relato hecho hasta aquí. El Ayuntamiento, quizás por no perder su ganada autonomía local o simplemente por amor propio a sus actos ejecutivos, resolvió obedecer la orden de la superioridad, no sin antes elaborar un descargo a fin de motivar un juicio positivo sobre la conducta y decisiones del Consistorio. Al fin y al cabo, la cuestión de fondo estribaba en el legítimo derecho de defensa de los acuerdos municipales.

Tras esta maniobra de gran sutileza, cómo no, escondíase una dilación bien calculada, esculpida por otras tantas ocasiones de desencuentro con la autoridad gubernamental. El benefactor, aparte del interesado individual, sería

16 Ibíd. Oficio del Gobierno Civil de la Provincia de Canarias, en Santa Cruz de Tenerife, al Alcalde Presidente, del 23 de marzo de 1910 .

17 Este facultativo, oficial del Cuerpo de Veterinaria Militar, pasó en poco tiempo a un nuevo destino dejando atrás cualquier interés en la capital isleña. Véase, al respecto, la Revista de Higiene y Sanidad Veterinaria (Tomo IV, $n^{\circ} .5$, agosto de 1914), que recoge, en su página 430, el listado formal de nombramientos en virtud de la R. O de 22 de julio de 1914 del Ministerio de la Guerra. Con referencia al citado, dice textualmente: "D. José Ostalé Bosque, de las brigadas de tropas de Sanidad Militar, al regimiento de Telégrafos". 
el juego político local y su proceder. Por esta razón, el informe de la Alcaldía al Gobierno Civil expone que:

“(...) Es un error de quien ha producido la denuncia, afirmar que por la Real Orden de 29 de Mayo de 1889 y por el reglamento de veterinarios militares, el Sr. Téllez está imposibilitado de prestar aquel servicio... cree esta Alcaldía que basta lo expuesto para que V. E. pueda apreciar la sinrazón de la denuncia"18.

No obstante, el intento fue fallido, por cuanto la ilicitud era manifiesta y trascendía la vertiente local. El Gobernador, en nuevo oficio, comunica al Ayuntamiento de manera taxativa que "el cargo que desempeña Don Juan Téllez se declare vacante y se anuncie su provisión por concurso con las formalidades prevenidas" 19 en ley. Aun se le hace presente al profesor veterinario militar, una vez la Alcaldía considera perdido el caso, ya en julio de $1910^{20}$. No le quedaba otra al Alcalde, don Felipe Massieu y Falcón, buen y avezado jurista aparte de la cabeza visible de la corporación municipal.

Sólo restaba convocar el dichoso concurso y disponer todas aquellas medidas conducentes a la transparencia procedimental y a la custodia de la legitimidad jurídica y procesal. Sin embargo, concluida la anterior singladura civil del veterinario militar, el Ayuntamiento se replegó a posiciones de austeridad, si bien el Gobierno Civil volvía a recordar la necesidad de dar cumplimiento a sus expresas órdenes.

"Sírvase V. S. manifestar á este Gobierno, por el primer correo, si ha cumplido mi providencia de 2 de junio último, comunicada

18 Legajo citado, exp. 49: Informe de descargo del 2 de abril de 1910 .

19 Ibíd. Oficio del Gobierno Civil de la Provincia de Canarias (negociado $2^{\circ}$. No ${ }^{\circ} .952$ ), del 8 de junio de 1910.

20 Ibíd. Oficio de la Alcaldía Constitucional de Las Palmas a don Juan Téllez López, del 12 de julio de 1910. el día 8 siguiente, declarando la vacante de la plaza auxiliar del Inspector de carnes de ese Ayuntamiento, desempeñada por D. Juan Téllez López y mandando proceder al anuncio y concurso para proveerla en forma legal"21.

Ante tal mandato, de imprevista contundencia, la Alcaldía se explaya en los pormenores que originaron su definitiva decisión de suprimir la auxiliaría:

“(...) El Ayuntamiento no ha acordado anunciar concurso para la provisión de esta plaza, sin duda porque la práctica ha demostrado que no es necesaria, pues el veterinario inspector basta para el desempeño del servicio de que se trata, y la Comisión municipal de presupuestos en el proyecto del que ha de regir para 1.911 propone la supresión de la referida plaza auxiliar" 22 .

Pronto se advierte la palmaria contradicción entre lo contenido en el informe de la Comisión de Abastos, de principios de año, y lo desarrollado por el Alcalde para pretextar la anulación del previsto concurso de provisión de un nuevo Profesor Veterinario en la ciudad, a finales del mismo. ¿Qué había ocurrido para ese giro tan pronunciado en la política de los ediles? La suerte corrida por el caso Téllez y la firme voluntad del Gobernador Civil, garante de la legalidad, son determinantes en el cambio de postura. Pero, existe un factor psicológico, y también de índole administrativa, que ayuda a una comprensión integral de lo sucedido. Refiérese a la cerrazón municipal a dar su brazo a torcer, a sacrificar su criterio en aras de una supuesta legitimidad jurídica; en fin, a mostrar sumisión, cuando de sus propias resoluciones

21 Ibíd. Oficio del Gobierno Civil de la Provincia de Canarias al Alcalde Constitucional, de fecha 11 de noviembre de 1910 .

22 Ibíd. Minuta de oficio del Alcalde en contestación al anterior, del 19 de noviembre de 1910 . 
se trataba, en asuntos de ámbito e influencia puramente local. En otro sentido, si no podía hacerse con la suya, pues ni lo uno ni lo otro, como diría el clásico.

La única perjudicada, obvio es decirlo, fue la ciudad de Las Palmas de Gran Canaria, porque, haciendo caso al precitado informe de la Comisión de Abastos, el volumen de trabajo de la veterinaria municipal iba en sensible aumento. Seguramente, este claro indicador social e higiénico-sanitario presionó en la inteligencia de la superioridad para que la Junta Provincial de Sanidad adjudicara, en sendos oficios de finales de $1913^{23}$, diferentes cargos de Subdelegados de Veterinaria en la urbe a favor de José Peig Castelló y Pedro Argüello del Fresno (uno, en el Distrito de Triana, y, el otro, en el Distrito de Vegueta).

Difícil transición, en todos lo sentidos, desde la improvisación inicial, en cuanto a la dotación de veterinarios capaces, hasta la superación material del posibilismo regeneracionista de principios de la centuria. La experiencia en el gobernalle administrativo, con un serio problema preventivo al fondo, tuvo que ser la que amonestara históricamente a los dirigentes locales, más proclives a la componenda política que al escrupuloso seguimiento de las instrucciones sanitarias o los reglamentos de la policía e higiene animal.

\section{El afán preventivo: vacunación e higiene ani- mal (1906-1909)}

Sería atrevido e injusto sentenciar que la municipalidad hiciera dejación de sus deberes en el ramo de la procuración de la sanidad animal, a pesar de lo observado en el punto previo. Desde luego, la saturación del servicio repercu-

23 Ibíd. Oficios del Gobierno Civil de la Provincia de Canarias a D. José Peig Castelló y D. Pedro Argüello del Fresno, respectivamente, fechados el 15 de diciembre de 1913. (Comunicación a la Alcaldía, por parte de la Delegación del Gobierno de S. M en Gran Canaria, del día 22 de diciembre del mismo año). tía negativamente sobre su calidad y alcance, si bien ello no faculta para despreciar una labor al completo, subestimando acciones o voluntades merecedoras, por otra parte, del reconocimiento histórico. A través de los expedientes venideros, el juicio avalará el rigor científico de las decisiones y la pulcritud de los programas de preservación y vacuna de las reses, así como la denuncia de intrusos en la profesión. Tres factores, elegidos a conciencia, con el objetivo de cimentar una estampa más fidedigna de lo realizado entre 1906 y 1909, período crucial de la incipiente oficina de la inspección municipal de veterinaria.

En determinados momentos, el Ayuntamiento o, por mejor decir, la Junta Municipal de Sanidad, intervienen en actividades que, lejos de verse así cómodamente insertadas en un ambiente de cobijo social e higienista, resultan fuente de conflictos inesperados, por improvisación o ignorancia de la legalidad vigente. Eso sí, quedan salvos la prevención y el ánimo sanitario. Esto ocurre, de modo singular, cuando el Consistorio es consultado acerca de la regulación de los programas de vacunación animal: pécase entonces de impetuosidad por someter el medio a un excesivo control, irreconciliable con el desarrollo normal de los acontecimientos.

Ejemplar de este espíritu es la campaña de la vacuna anticarbuncosa en el ganado vacuno a mediados de 1906. El veterinario militar, Cristóbal Lara, en una correcta y oportuna comunicación, dirigida a la Alcaldía Constitucional, inquiere a la autoridad local sobre "las medidas que se han de tomar con dicho ganado para ponerlo en conocimiento de sus dueños" ${ }^{24}$. Paradigmática representación de la responsabilidad voluntarista de los veterinarios de la época, puntillosos con la ejecución de la normativa afecta a sus funciones, amén de adiestrados individuos en la relación con las instituciones sanitarias. La Comisión Permanente de la Junta

24 AHPLP, Ayuntamiento, Sanidad, legajo 8, expediente 15. Comunicación del 3 de agosto de 1906. 
Municipal de Sanidad, obligada a dictar unas órdenes claras y comprehensivas, realiza una aparatosa exhibición del celo competencial. No obstante, la fineza del propósito, y eso desconocíase en el instante de la redacción, se desmarca de la realidad de la explotación de las vaquerías insulares y va mucho más allá, quizá demasiado para lo que se le solicitaba.

"Sometido á la deliberación de la comisión permanente..., el oficio dirigido por V. á esta Alcaldía... se acordó manifestar á V. que aparte el cumplimiento exacto de las disposiciones contenidas en los artículos 65 y 57 del Reglamento de 3 de julio de 1904 sobre policía sanitaria de los animales domésticos, se le exija la previa presentación á la Alcaldía de un local, en las debidas condiciones, en el cual han de efectuarse las inoculaciones y permanecer aislados los animales durante el período de observación que es el de treinta días; quedando, además prohibida la expendición de la leche de las vacas..." 25 .

Conforme al Estudio geográfico-económico de la isla de Gran Canaria (1916), de José Miranda Guerra, el ganado vacuno se destinaba "secundariamente a las necesidades de la alimentación, para el suministro de leches y fabricación de quesos" 26 , por ser escaso en número y, sobre todo, dedicado a la agricultura como fuerza de tracción. Esto es, como cabe deducir del anterior documento, prohibir durante largo tiempo el provecho comercial de los lácteos suponía, de hecho, el desabastecimiento de la población y, en paralelo, la ruina de los ganaderos, por más que los productos importados engrosaran el mayor vector de consumo -por ejemplo, para el caso, los botes de leche condensada, que hicieron furor en la época-, puesto

25 Ibíd. Oficio de la Alcaldía Constitucional de Las Palmas a don Cristóbal Lara, del 8 de agosto de 1906.

26 MIRANDA GUERRA, J. (2004). Estudio geográfico-económico de la isla de Gran Canaria. Santa Cruz de Tenerife, Eds. Idea, pág. 50. que no debe incluirse en tal orden el artículo de la leche fresca para el abasto diario. Informado de este y otros extremos, Cristóbal Lara vocea la injusticia pretendida y fomenta la sensatez de las directrices de los expertos municipales:

“(...) a lo cual debo manifestar a V. E., en primer lugar, que con arreglo a la Ley de Policía Sanitaria todo animal vacunado puede quedar en poder de su dueño sin sacarlo de su establo o dentro de su finca; en segundo lugar, que la vacuna preservativa anticarbuncosa es completamente inofensiva y no produce alteración fisiológica ninguna, solamente en algunas reses extenuadas podrá producir un pequeño estado febril durante un día o dos después de la segunda vacunación... y además, no habiendo alteración ni en la cantidad ni calidad de la leche segregada por dichos animales, como lo he demostrado en las 115 reses que he vacunado en San Lorenzo y 26 en Santa Brígida..., no debe inutilizarse dicha leche"27.

Reconforta comprobar como, de veras, se seguía adelante con el calendario de vacunaciones entre la población ganadera de la comarca. Garantizada objetivamente esta principal cuestión, los razonados criterios del veterinario militar, metido a tareas civiles, sorprenden a la ingenua inquietud del Ayuntamiento. A buen seguro, otro tenor hubiera sido si el oficio capitalino hubiera tenido por redactor a don Julio Orive, o a cualquier otro perito en la medicina veterinaria, evitándole al Consistorio el descrédito al que se expuso. Fuera de esto, el espíritu higienista a machamartillo intentó colmar una preocupación que, de suyo, sobrepasaba la esfera de la ciencia veterinaria para adentrarse en el mundo médico. Si ha de buscarse un error histórico, tal vez fuera éste, la confusión entre los modos de la higiene animal y la sanidad humana.

27 Expediente cit. Comunicación de Cristóbal Lara al Alcalde, del 30 de noviembre de 1906. 
La doctrina científica, en el páramo de la tutela de la salud general, acredita el rigor de las medidas arbitradas por la Junta Municipal de Sanidad, siempre y cuando hubiera riesgo cierto de zoonosis, o contagio posible desde el ganado al hombre. Cómo no, ésta era la honda y grave excitación de los responsables de la oficina local. Y, en su consecuencia, no habría manera de reprochar la actitud mostrada, no así la intromisión de los referentes de la medicina preventiva en la hermana disciplina veterinaria.

De intrusismo profesional, exactamente, versan las denuncias presentadas por don Cristóbal Lara ante la Subdelegación de Veterinaria de Las Palmas, en junio de 1906. Mismo individuo, pues, que penetrado de los más altos intereses, arremete contra la emergente clientela y, especialmente, contra los supuestos profesores veterinarios que ofertan unos servicios delictivos, ribeteados de una capacitación ilegítima, carente de la necesaria titulación.

"El que suscribe Profesor Veterinario Militar tiene el honor de denunciar a V. a los intrusos José Barrera Pérez, Juan Hernández del Hoyo y Francisco Hernández Santana, con establecimiento público el primero en la carretera de Tafira, el segundo en la calle de los Balcones y el tercero en el paseo de los Castillos, donde hierran y curan animales sin tener título que los autorice por lo cual Suplico se tramite esta denuncia al Sr. Alcalde Constitucional de esta Ciudad para que requiera a dichos intrusos" $" 28$.

De tiempo atrás, e incluso desgraciadamente se perpetuaría bastante más allá de la fecha consignada, el intrusismo en las tareas de los titula-

28 AHPLP, Ayuntamiento, Sanidad, legajo 8, expediente 24. Carta de D. Cristóbal Lara al Subdelegado de Veterinaria en Las Palmas, del 25 de junio de 1906. Éste, a su vez, remite oficio al primer edil ese mismo día, comunicando lo anterior. dos sanitarios, fueran médicos o veterinarios ${ }^{29}$, como es el caso, supuso una lacra en el control de la higiene pública canaria. No había mayor rubor en constatar el influjo de estos curanderos o sanadores por toda la geografía isleña, antes, al contrario, la literatura de los cronistas documenta la presencia de estos personajes campando a sus anchas, con prácticas pseudocientíficas y, las más de las veces, contorneadas de aspectos mágico-religiosos propios de estadios atrasados de la civilización humana. Así, Domingo J. Navarro, en sus sabrosos Recuerdos de un noventón $(1895)^{30}$, dedica un amplio número de páginas a relatar los variopintos métodos y consejas utilizados en los actos de curación.

Cabe, entonces, un examen positivo de la severa e intachable conducta del veterinario militar, don Cristóbal Lara. Por otro lado, sirve para mostrar que, cuando se echaba en falta un organismo próximo que rigiera y velara por el correcto funcionamiento de las instituciones sa-

29 A mediados de 1910, Agustín Fornells Plana, del que ya hablaremos más adelante, y Joaquín López Ruiz instauran en Santa Cruz de Tenerife una Clínica Veterinaria muy necesaria y mejor acogida por los profesionales de la cría de ganado y, en general, por todo aquel preocupado por la salud animal. Pero, esta noticia, saludada desde los editoriales de La Asociación agrícola, una revista importante del ramo cuyo secretario de redacción fue el Perito Agrícola don Pedro Pelluz Sánchez, también es convenientemente contextualizada en la situación de intrusión en las labores propias de la ciencia veterinaria: "Tienen grandísima importancia los intereses pecuarios... para que se dejen abandonados á manos inexpertas, como son las de los que vienen practicando estas operaciones [herrajes y cura de males]... que hasta hoy han usado y abusado de la tolerancia, buena fe y falta de unión de los dueños de ganados, los cuales no teniendo en cuenta la importancia de sus capitales invertidos en máquinas de sangre, no tan sólo no protestaban sino que hasta toleraban con cierta satisfacción cuando alguno de estos chupópteros de la Veterinaria denigraba á nuestros compañeros, y amenazaban á sus clientes con no herrarles las caballerías, si alguno, más ilustrado ó más cuidadoso de lo suyo que otros, se atrevía a llamar al Veterinario para la consulta y consiguiente tratamiento de las enfermedades de sus ganados" ( $\mathrm{n}^{\circ} .22$, del 10 de agosto de 1910, pág. 348. Las cursivas son nuestras).

30 NAVARRO, Domingo J. (1991). Recuerdos de un noventón. Las Palmas, Eds. del Cabildo Insular de Gran Canaria, pp. 85-92. 
nitarias o higiénicas, la buena voluntad de unos cuantos comprometidos ponía coto al desgarro sangrante de la práctica no titulada. En boca de todos estaba que la albeitería ${ }^{31}$, tolerada al amparo de la costumbre, principiaba una nueva etapa, diferente en la valoración social y administrativa. En este sentido, lo antaño sancionado y celebrado, ahora pertenecía a un primitivismo pronto a desaparecer, y que, por encima de cualquier juicio personal, debía ser limitado hasta llegar a exterminarlo de las tradiciones más acendradas en el campo canario.

Por una tercera vía, el solo hecho de acometer una denuncia, como la reflejada, representa un gesto de modernidad en la rueda administrativa del municipio capitalino. La solvencia de criterios y la consiguiente honra de saberse cumplidores de la normativa legal son harto elocuentes de un cambio significativo en el actuar de las instituciones. Por fin, la policía e higiene animal son algo más que los rubros con que se vestía la oficina veterinaria de la ciudad, o al menos la Subdelegación del sector, dependiente del despacho del Gobierno Civil de la Provincia de Canarias.

Se llevan explicados algunos tipos ejemplares del voluntarismo veterinario, en un período fundacional y determinante de la disciplina en Gran Canaria; sin embargo, el que hemos dejado para este postrero lugar dignifica en un modo alternante, ya que demuestra que se logró un importante grado de coordinación entre los laboratorios oficiales y la acción inspectora de la administración local. El binomio de la teoría y la práctica, o el de la ciencia y la ejecución de sus diagnósticos, fue un desiderátum que no siempre estuvo en la mano de los que lo procuraban. Por esta razón, el historiador no debe ocultar la satisfacción del hallazgo de tal comprensión institucional.

Tres son los organismos, envueltos en la madeja de instituciones, que se afanan y ufa-

31 Cfr. el clásico SANZ EGAÑA, Cesáreo (1941). Historia de la Veterinaria Española. Madrid, Espasa-Calpe. nan por encontrar un principio unitario de actuación en el bien de la atención sanitaria de la urbe. A una parte, el Laboratorio Químico Municipal, de feliz apertura en el último trimestre de $1904^{32}$, que es el que da la voz de alerta higiénica a través de los resultados obtenidos de algunas muestras al parecer contaminadas. El segundo, el Ayuntamiento de Las Palmas de Gran Canaria, responsable de materializar las medidas correctoras dispuestas por el tercer interlocutor: la Delegación de Gobierno para el grupo oriental del archipiélago. Precisamente, esta última emitió un interesante oficio a la Alcaldía, el 4 de junio de 1909, firmado por Mariano Quintero, que justifica y legitima el afán preventivo de los munícipes:

"En vista de su atenta comunicación de fecha 2 del actual, participándome que el vecino del pueblo de Santa Brígida José Rodríguez Monzón expende la leche en esta Ciudad, que según resulta de los análisis de la misma practicados por el Laboratorio Municipal, contiene gérmenes nocivos á la salud, he acordado, de conformidad con lo propuesto por V. S., que un Profesor Veterinario por V. S. designado, pase á la referida población y en unión del titular Veterinario de la misma, sean reconocidas minuciosamente las reses vacunas de que se surte de leche el expresado Rodríguez, expidiendo la correspondiente Certificación del resultado del reconocimiento que deberán remitirme..." 33 .

Sin duda alguna, la coordinación institucional estaba penetrada de la mejor de las in-

32 Exactamente, el 10 de noviembre de 1904. Cfr. MARTÍN DEL CASTILLO, Juan Francisco (1995) "Una noticia histórica: la inauguración del Laboratorio Químico Municipal de Las Palmas (1904)". Aguayro, 212, pp. 12-15; id. (1996) Los primeros laboratorios de Las Palmas (19041926). (Una aproximación). Las Palmas de Gran Canaria, Ayuntamiento, pág. 41.

33 AHPLP, Ayuntamiento, Sanidad, legajo 8, expediente 56. Oficio de la Delegación Especial del Gobierno de S. M. en Gran Canaria, Lanzarote y Fuerteventura. 
tencionalidades y, por tal motivo, no podía ni debía quedar vacía de propósitos y contenidos. Informado el principal edil de la reciedumbre ejecutiva de la Delegación de Gobierno, no tarda en descubrirse el porqué de la primera denuncia municipal, en este caso anticipatoria de las posteriores decisiones:

“(...) le manifiesto, que según me contesta el Alcalde de la expresada villa [Santa Brígida] no existe allí Veterinario Titular, pero que al personarse el que sea designado por V. S. se le facilitarán todos los auxilios que le sean precisos para el mejor desempeño de su cometido" ${ }^{34}$.

Se deduce, por tanto, que la carga inspectora remitía a la fuerza al Ayuntamiento capitalino, al desconocerse las funciones de un veterinario en el municipio de medianías. En otro sentido, también obtienen un cabal desahogo comprensivo los episodios ya asomados en este estudio, matizados por el actuar de profesores militares en esferas que, en principio, estarían lejos de sus labores profesionales. Tanto lo uno como lo otro, se resuelven en un inquietante voluntarismo de los individuos concernidos en la trama sanitaria y preventiva. Dicho lo cual, no es óbice para reconocer que, en este asunto, la comunicación entre diferentes departamentos administrativos ha de ser saludada con auténtico orgullo histórico.

\section{La organización del servicio de Higiene Pe- cuaria y Sanidad Veterinaria (1910)}

La evidencia documental ha sustanciado un enorme esfuerzo, por parte de las instituciones locales, y en encomioso celo voluntarista en el funcionamiento de la veterinaria insular, especialmente en la capital grancanaria, durante un sexenio al completo. En 1910, el estado de

34 Ibíd. Nuevo oficio de la Delegación Especial del Gobierno al Alcalde Presidente, fechado el 12 de junio de 1909. cosas habría de experimentar un significativo giro provincial, puesto que los organismos de la política archipielágica son los fautores de la inflexión. Como es natural, al provenir la disposición del ejercicio vertical de la función pública, no habrá de librarse del sambenito ordenancista de la historia institucional española; sin embargo, pese a este contratiempo, los nuevos aires que se respiran en la veterinaria canaria son más que suficiente reclamo para un ajustado recuerdo historiográfico.

A veces, un gesto, por mínimo que pareciere, bendice un tiempo distinto, en términos relativos, en el quehacer administrativo. Justamente, esto es lo que ocurre con la serie de circulares emitidas por la rimbombante Jefatura de Fomento y Presidencia del Consejo Provincial de Agricultura y Ganadería. Al fin, se vive un momento de reformismo desde las más altas instituciones de Canarias, y no a la inversa, auspiciadas desde el ámbito local, como era lo usual. Una de aquéllas, la datada en el día 20 de abril de 1910, detalla el expresado sentir, amén de presentar al máximo responsable de la inspección animal:

"Habiendo tomado posesión del cargo de Inspector de Higiene Pecuaria y Sanidad Veterinaria de esta Provincia, don Agustín Fornells, en virtud de oposición, urge organizar los importantes servicios que referentes a la Ganadería determina el capítulo $2^{\circ}$. del R. D. de 25 de Octubre de 1907. Aparte de los servicios que este funcionario deberá llevar á cabo cuando se instale la Estación Pecuaria, en la actualidad y de momento, su principal misión es prevenir las enfermedades infectocontagiosas que se puedan presentar en los ganados, y evitar su propagación en el caso desgraciado de que alguna se presentase" 35 .

35 AHPLP, Ayuntamiento, Sanidad, legajo 8, expediente 66. Circular de la Jefatura de Fomento y Presidencia del Consejo Provincial de Agricultura y Ganadería - Canarias, firmada por A. Padilla, y dirigida al Alcalde de Las 
El papel timbrado y el ringorrango de los sellos de la oficina, incluso, destapan una emocionante etapa de proyección en el ramo veterinario. La provisión de la plaza del Inspector y las ansias por cubrir las lagunas tradicionales del servicio, de lo que da cuenta el ánimo de instaurar una Estación Pecuaria para el conjunto insular, son, a su manera, la patente realidad de una perspectiva novedosa en el cuidado sanitario de los animales. Una vez en el despacho, don Agustín Fornells prontamente dictó instrucciones acerca del control de determinadas infecciones, en un tono pedagógico que habla a las claras del espíritu entusiasta y entregado del neófito:

"Habiéndose presentado la Durina en algunas provincias de España... cumpliendo lo ordenado por la superioridad y el acuerdo tomado por este Consejo provincial de Agricultura y Ganadería, en sesión celebrada el día 30 de Abril próximo pasado, de dar á conocer los síntomas principales y más característicos de la mentada infección, esta Inspección de Higiene pecuaria y Sanidad Veterinaria, se complace en comunicar á V., suponiendo sea profano á la profesión de Veterinaria, la forma con que generalmente se suele presentar dicho padecimiento infecto-contagioso. La Durina conocida también con los nombres de mal de los reproductores, venéreo caballar, sífilis equina, parálisis de los reproductores, etc., etc., es una enfermedad contagiosa, ocasionada por unos parásitos de la sangre, conocidos con el nombre de tripanosomas, reconociendo por causa la infección en el acto de la monta ó

Palmas. Sobre el "Cuerpo de Inspectores de Higiene Pecuaria y Sanidad Veterinaria”, creado precisamente en 1910, cfr. CAMARERO RIOJA, Fernando (2004) "Investigación acerca de la fundación de los Colegios de Veterinarios en España", Actas del X Congreso Nacional, IV Iberoamericano y I Hispanoluso de Historia de la Veterinaria, Junta de Extremadura (Consejería de Cultura), Badajoz, pp. 187-193 (http://www5.colvet.es/aehv/pdf/Libro\%20de\%20actas\%20 Olivenza.pdf). coito, siendo cuasi exclusiva de los caballos y asnos y sus hembras" 36 .

Este didactismo, bien recibido por otra par$\mathrm{te}^{37}$, no es una arbitrariedad o presunción del Inspector Fornells. Opuestamente, supone un completo acierto en la medida que procura una herramienta valiosísima a los ediles de los numerosos municipios canarios que no contaban, entre su personal funcionario, con un experto en la materia. De primera mano, hemos podido comprobar como en Santa Brígida se hizo notar esta ausencia, siendo causa y motivo de daño a la producción lechera y lamento de las instituciones capitalinas al detectar microbios nocivos en los ensayos analíticos practicados a la leche llegada de la villa. Es más, hubo de desplazarse un técnico de la ciudad para poner orden entre las reses vacunas de un señalado ganadero (Rodríguez Monzón).

Se ha de convenir que en 1910 se principió un sendero de marcada seriedad organizativa en el ámbito de la medicina veterinaria, tanto en el nivel local, dotándose de titulados para atender el servicio, como en el plano provincial, apoyando y dirigiendo las campañas preventivas o inspectoras a todas luces imperiosas para

36 Ibíd. Circular de la Inspección de Higiene Pecuaria y Sanidad Veterinaria - Canarias al Alcalde de Las Palmas. Fechada el 4 de mayo de 1910, en Santa Cruz de Tenerife. De esta labor se hace eco, incluso, la Revista de Higiene y Sanidad Veterinaria, disponiendo elogiosas palabras hacia el Inspector: "D. Agustín Fornells, con paciencia y entusiasmo incansables, va consiguiendo vencer la inercia de los ganaderos de Canarias, arrancándolos de rutinas absurdas y encaminándolos por los derroteros que la ciencia señala" (Tomo I, nº. 9, de diciembre de 1911, pág. 272).

37 Los periódicos de la época recogían, prestándose a esta función pedagógica de Fornells y Plana, las palabras pronunciadas en los actos de divulgación científico-técnica del Inspector, cfr. Gaceta de Tenerife, del 10 de enero de 1912 ( $\mathrm{n}^{\circ}$. 648), que informa de "Una conferencia" —así reza el suelto - en los salones de la Real Academia de Medicina, en los siguientes términos: "[los] concurrentes al acto felicitaron calurosamente al señor Fornells por su erudito y acabado trabajo, dechado de perfección y saturado de ciencia" (pág. 3). Por cierto, el tema de la exposición era la epizootia de carbunco o bacera. 
controlar los males infecciosos de los animales, verdadera cruz de los explotadores industriales y de los veterinarios. Evidencia de ello es el próximo documento, anticipando una conducta higienista de amplio espectro, indudablemente pocas veces vista en el archipiélago.

“(...) dispone que por el Inspector de Higiene Pecuaria y Sanidad Veterinaria, se proceda á reconocer y recontar pronto y con escrupulosidad, todo el ganado caballar y asnal apto, empleado ó no, para la reproducción que haya en esta Provincia, al objeto de comprobar su estado de sanidad" 38 .

\section{CONCLUSIONES}

Esta ha sido una sucinta cala en la historia sanitaria de la urbe capitalina de Las Palmas de Gran Canaria, en la periferia insular española y, además, en un tiempo de renovación evidente, aurora de una época de reforma y regeneracionismo. Encontrar las pautas historiográficas que iluminan dicho período ha sido también el propósito manifiesto del estudio que ahora acaba, siempre y cuando no se pierda de vista la servidumbre que supone su índole parcial, sugeridora más que exhaustiva, propia de un ensayo histórico. No obstante, llega el momento de la recapitulación, de poner orden y otear desde lo alto para discernir lo relevante de lo anecdótico, lo estructural de lo pasajero y, en definitiva, lo que asemeja constante temporal de lo que es débito coyuntural.

Ya, en el proemio del presente, barruntábase algún que otro principio definidor de la trama veterinaria. En este instante postrero, cabe su certificación como realidad certera. Decíamos que la prevención higiénica y el proyectismo

38 Legajo 8, expediente 66, ya citado. Circular de la Jefatura de Fomento y Presidencia del Consejo Provincial de Agricultura y Ganadería - Canarias al Alcalde de Las Palmas. Firmada por el Vicepresidente $1^{\circ}$., A. Padilla, en Santa Cruz de Tenerife, el 6 de mayo de 1910. El motivo era la posible proliferación de la durina. reformista, como hijos del regeneracionismo político y social, habrían de ocupar lugares singulares en el desarrollo de la medicina y la veterinaria insulares. Ello era verdad en los albores del nuevo siglo y, por supuesto, en el despertar de la segunda década del mismo. Hitos de esta empresa sanitaria son, verbigracia, la demanda de proyecciones por parte del Ayuntamiento, al igual que el anhelo de extender los servicios de limpieza y desinfección por toda la urbe, alcanzando las barriadas extremas, tradicionalmente desatendidas. Tropezaría la voluntad municipal con la escasez presupuestaria, otro fenómeno constante por desgracia en aquellos momentos, suplida con la alegría del voluntarismo de los profesionales y el entusiasmo de las gentes del ramo sanitario.

La veterinaria local surca un camino parecido al de la medicina, sin embargo la desestructuración del servicio hizo muy difícil adquirir el estatus social y aun legal del que se enorgullecía el médico. Costó tiempo y ciertos conflictos jurídicos la definición de las atribuciones públicas del Profesor Veterinario en la capital grancanaria, tocada en ocasiones de amateurismo e improvisación en la dotación de las supuestas plazas de personal experto. Se ha cotejado que la ciudad, aunque sobre el papel fueran dos, disponía de una única oficial, a la que acompañaba otra de extraña categoría, admitida por el notable incremento de las actividades de policía animal, sobre todo en la Plaza del Mercado y en el Matadero municipal, para lo cual se instituyó el cargo de Inspector de Carnes ad hoc.

Una vez conseguida la traza básica del servicio veterinario, alrededor de 1910, la organización de la Higiene Pecuaria tornó a convertirse en requisito provincial, objeto antaño perseguido pero que demoróse por algún tiempo, dándose la circunstancia de que la vertebración de la sanidad veterinaria principió en los municipios isleños y luego concluyó con el ordenamiento de la Jefatura de Fomento y Presidencia del Consejo Provincial de Agricultura y Ganadería de Canarias. Mientras ello producíase, la labor 
de control de las enfermedades y el cuidado de los animales afectados, así como las funciones reglamentadas por la ley de Instrucción General de Sanidad de 1904, no sufrían merma alguna. Con todo, hay que advertir que la ausencia de veterinarios, en los pagos y villas de los alrededores de la capital, obligaba a una incesante actividad de los titulados públicos; y cuando no se podía arbitrar tal proceder, los veterinarios militares venían en ayuda de la situación, como se ha comprobado reiteradamente en el texto, soportando sobre sí campañas de vacunación preventiva, aparte de otros menesteres propios de la profesión.

La municipalidad tuvo, por la fuerza de los acontecimientos, que arrostrar tan anómalo plan de actuación en la procura higiénica y así hubo de dar un mínimo criterio de seriedad en la práctica sanitaria, a fin de marginar el intrusismo rampante y fortalecer las pilastras de la policía animal. No bien salida del embate, debió aunar voluntades y juicios para el perfecto entendimiento de lo qué era un veterinario acreditado y cuáles sus funciones de atribución. Pormenores que parecen extrañamente ridículos al presente histórico, pero que en la época volvíanse más que urgentes y necesarios. Incluso, los ediles debieron echar mano de la Inspección Municipal de Sanidad para orientar las facultades veterinarias, ocasionando tal ejemplo contratiempos insospechados al Consistorio, entrometido en suertes ajenas al empeño médico. Sin embargo, la excepción historiográfica da cuenta de la quebradiza definición de la veterinaria como ciencia, al menos para Las Palmas de Gran Canaria.

\section{BIBLIOGRAFÍA}

AVILES FARRE, JUAN et alii 2002. Historia política, 1875-1939. Eds. Istmo (Col. "Fundamentos", Serie "Historia de España, XVII"). Madrid.

CAMARERO RIOJA, F. 2004. Investigación acerca de la fundación de los Colegios de Veterinarios en España. Actas del X Con- greso Nacional, IV Iberoamericano y I Hispano de Historia de la Veterinaria. Junta de Extremadura (Consejería de Cultura). Badajoz, pp. 187-193. (http://www5.colvet. es/aehv/pdf/Libro\%20de\%20actas\%20Olivenza.pdf).

CORDERO DEL CAMPILLO, M. 1996. Albeytería, mariscalia y veterinaria: orígenes y perspectiva literaria. Secretariado de Publicaciones (Universidad de León), León.

GARCÍA MADERAL, C. 2000. Los animales en el mundo de brujas y sanadores. $V$ Jornadas Nacionales de Historia de la Veterinaria. Col.legi Oficial de Veterinaris de Barcelona, Barcelona.

GRATACOS I MASANELLA, JAUME et alii 2000. Los menescales y las Menescalías desde el siglo XII al siglo XX. V Jornadas Nacionales de Historia de la Veterinaria. Col.legi Oficial de Veterinaris de Barcelona, Barcelona.

HUERTAS GARCÍA-ALEJO, R. 2000. Política sanitaria: de la Dictadura de Primo de Rivera. a la II ${ }^{\mathrm{a}}$. República. Revista Española de Salud Pública. 74: 35-43.

La asociación agrícola [revista]. 1910. 22: 348. MARTÍN DEL CASTILLO, JUAN FRANCISCO. 1995. Una noticia histórica: la inauguración del Laboratorio Químico Municipal de Las Palmas (1904). Aguayro, 212: 12-15.

- 1996. Los primeros laboratorios de Las Palmas (1904-1926). (Una aproximación). Eds. del Ayuntamiento, Las Palmas de Gran Canaria.

- 2005. Los orígenes del Instituto Provincial de Higiene de las Canarias Orientales y la sanidad municipal (1926-1927): cambios estructurales y asistenciales. Asclepio. LVII (2): 129-150.

- 2009. La Voluntad de Hipócrates. Principales episodios de la Junta Municipal de Sanidad y la salud pública en Las Palmas de Gran Canaria, 1875-1915. Eds. Idea y Sociedad Canaria de Historia de la Medicina, Santa Cruz de Tenerife. 
MIRANDA GUERRA, J. 2004. Estudio geográfico-económico de la isla de Gran Canaria. Eds. Idea. Santa Cruz de Tenerife.

NAVARRO, DOMINGO J. 1991 [1895]. Recuerdos de un noventón. Eds. del Cabildo Insular de Gran Canaria. Las Palmas de Gran Canaria.

PÉREZ GARCÍA, J. M. 1995. El Cuerpo de Veterinaria Militar, 1845-1995. Ministerio de Defensa, Madrid.
Revista de Higiene y Sanidad Veterinaria. Tomo I (9) de 1911 y tomo IV (5) de 1914.

RODRÍGUEZ GARCÍA, M. 1994. Historia da Escola de Veterinaria de Compostela. Universidad de Santiago. Santiago de Compostela.

[Sin autor] 1912. Una conferencia. Gaceta de Tenerife. 648 (10 de enero de 1912).

SANZ EGAÑA, C. 1941. Historia de la Veterinaria Española. Espasa-Calpe, Madrid. 
